\title{
Cellular effectors mediating Th17-dependent clearance of pneumococcal colonization in mice
}

\author{
Zhe Zhang, Thomas B. Clarke, and Jeffrey N. Weiser \\ Department of Microbiology, University of Pennsylvania School of Medicine, Philadelphia, Pennsylvania, USA.
}

\begin{abstract}
Microbial colonization of mucosal surfaces may be an initial event in the progression to disease, and it is often a transient process. For the extracellular pathogen Streptococcus pneumoniae studied in a mouse model, nasopharyngeal carriage is eliminated over a period of weeks and requires cellular rather than humoral immunity. Here, we demonstrate that primary infection led to TLR2-dependent recruitment of monocyte/macrophages into the upper airway lumen, where they engulfed pneumococci. Pharmacologic depletion of luminal monocyte/macrophages by intranasal instillation of liposomal clodronate diminished pneumococcal clearance. Efficient clearance of colonization required TLR2 signaling to generate a population of pneumococcal-specific IL-17-expressing CD4 ${ }^{+} \mathrm{T}$ cells. Depletion of either IL-17A or $\mathrm{CD}^{+} \mathrm{T}$ cells was sufficient to block the recruitment of monocyte/macrophages that allowed for effective late pneumococcal clearance. In contrast with naive mice, previously colonized mice showed enhanced early clearance that correlated with a more robust influx of luminal neutrophils. As for primary colonization, these cellular responses required Th17 immunity. Our findings demonstrate that monocyte/macrophages and neutrophils recruited to the mucosal surface are key effectors in clearing primary and secondary bacterial colonization, respectively.
\end{abstract}

\section{Introduction}

Acute respiratory infection remains a leading cause of mortality worldwide. Recent experience in the developing world has revealed the importance of immunization against a single pathogen, Streptococcus pneumoniae (the pneumococcus), in lowering the incidence of respiratory tract infection and overall childhood mortality (1). As is the case for many mucosal pathogens, colonization not only precedes all pneumococcal diseases but also serves as a prerequisite for the spread of the organism within the community (2-4). Longitudinal carriage studies have shown that colonization of the upper respiratory tract is a dynamic process, with most children colonized serially with single or even multiple serotypes of the pneumococcus (5). Each colonization event may persist from days to months (6). Host factors that lead to the clearance of the bacterium from its commensal niche on the mucosal surface of the human nasopharynx are not well defined.

Prior studies have emphasized the importance of humoral immunity in protection from this predominantly extracellular pathogen (7). Antibodies to pneumococcal capsular polysaccharides define the 91 known serotypes, are opsonic, and may confer serotype-specific protection. Systemic immunization with capsular polysaccharide-based vaccines induces high levels of serum antibody that are sufficient to prevent the acquisition of strains in a serotype-specific manner (8-10). However, in experimental human carriage studies, colonization generates minimal anticapsular antibody, and clearance is not temporally associated with the development of serotype-specific immunity $(6,11)$.

Conflict of interest: The authors have declared that no conflict of interest exists. Nonstandard abbreviations used: $\mathrm{APC}$, allophycocyanin; $\mathrm{Cl}_{2} \mathrm{MDP}$, clodronate; LAMP-1, lysosomal marker lysosome-associated membrane protein-1; MCP-1, monocyte chemotactic protein-1; MOMA-2, monocyte/macrophage marker; PerCP, peridinin chlorophyll protein.

Citation for this article: J. Clin. Invest. 119:1899-1909 (2009). doi:10.1172/JCI36731.
Moreover, the overall decrease in rates of pneumococcal carriage that occurs with increasing age beyond early childhood occurs in a largely serotype-independent manner (12). In model pneumococcal colonization of mice, clearance of bacteria from the upper airway requires $\mathrm{CD}^{+}$but not $\mathrm{CD}^{+} \mathrm{T}$ cells and is independent of antibody $(11,13-15)$. Trzcinski et al. have recently confirmed that antigen-specific $\mathrm{T}$ cell immunity is sufficient to protect against pneumococcal colonization in mice (16). These observations suggest that cellular rather than humoral immunity may be necessary for natural immunity that promotes the clearance of pneumococcal colonization. In this regard, the depletion of $\mathrm{CD}^{+} \mathrm{T}$ cells in HIV-positive children could account for their elevated rates of pneumococcal carriage and disease (17).

Additional studies using genetic mouse models show that clearance of colonization is delayed in the absence of TLR2, which promotes signaling in leukocytes and other cells in response to lipid-modified pathogen-associated molecular patterns (18-20). Similarly, mice with a mutation affecting TLR4 signaling show diminished responses to this pathogen's only known toxin, pneumolysin, and are more susceptible to pneumococcal colonization following nasopharyngeal challenge (21). Pneumolysin has also been implicated as a factor triggering the migration and activation of $\mathrm{CD}^{+} \mathrm{T}$ cells $(22)$. The recognition of a TLR- and $\mathrm{CD}^{+}$ $\mathrm{T}$ cell-dependent immune mechanism has left in question the nature of the effector(s) mediating antibody-independent clearance. Malley et al. have shown that depletion of IL-17 blocks the protective effect of mucosal immunization with a killed whole-cell vaccine, indicating the importance of the Th17 subset of $\mathrm{CD}^{+} \mathrm{T}$ helper cells $(14,15,23)$.

Pneumococcal colonization induces an acute inflammatory response, with a predominance of neutrophils in the nasal spaces during initial colonization ( $<72$ hours) (18). The antimicrobial activity of luminal neutrophils contributes to the processing of bacterial antigen and its delivery to the nasal-associated lymphoid 
A

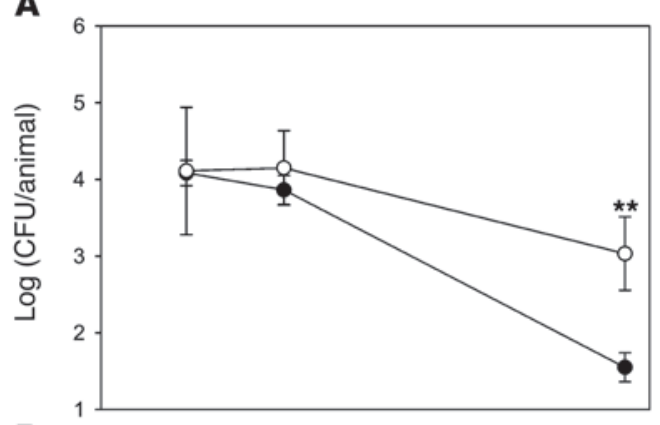

B

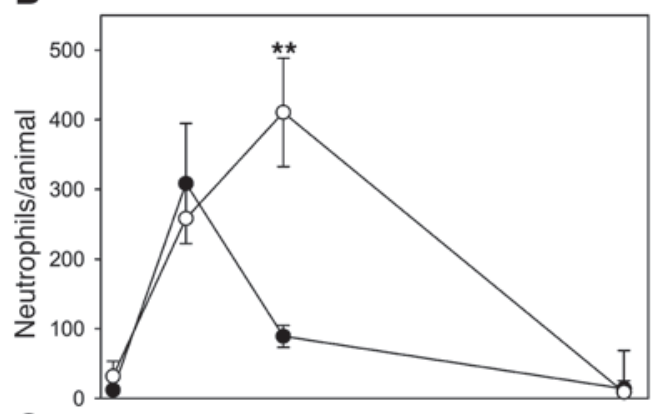

C

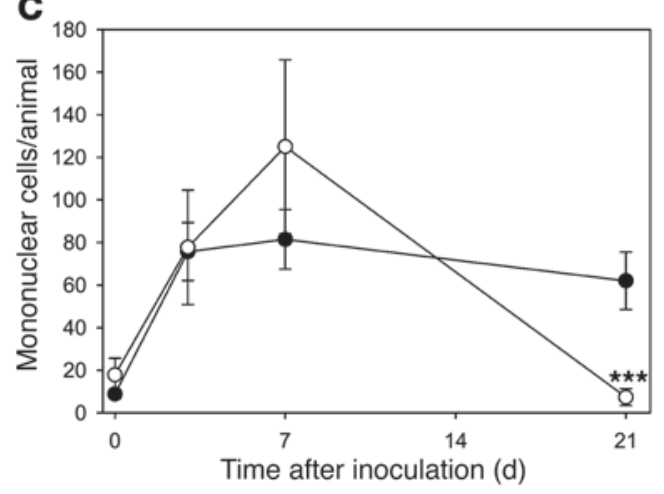

D

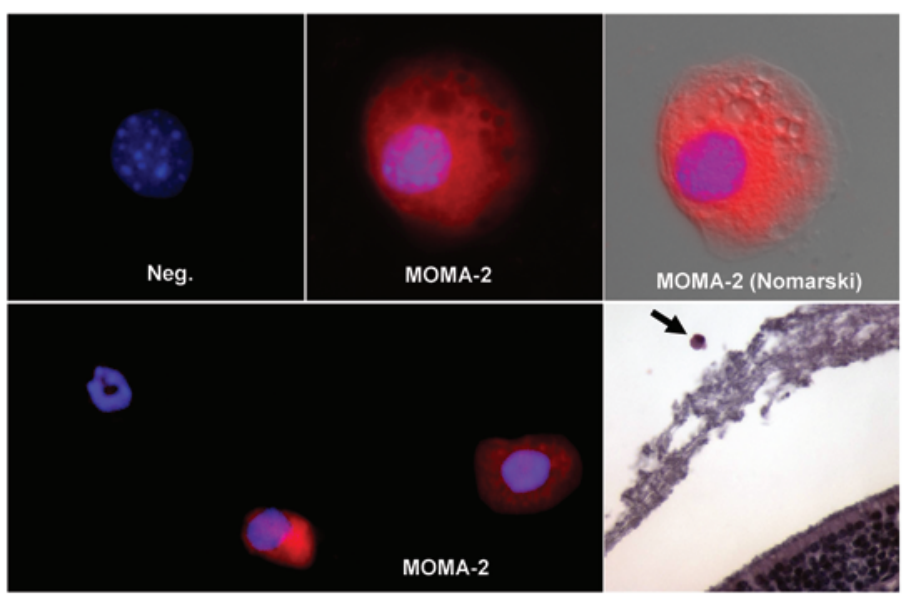

E
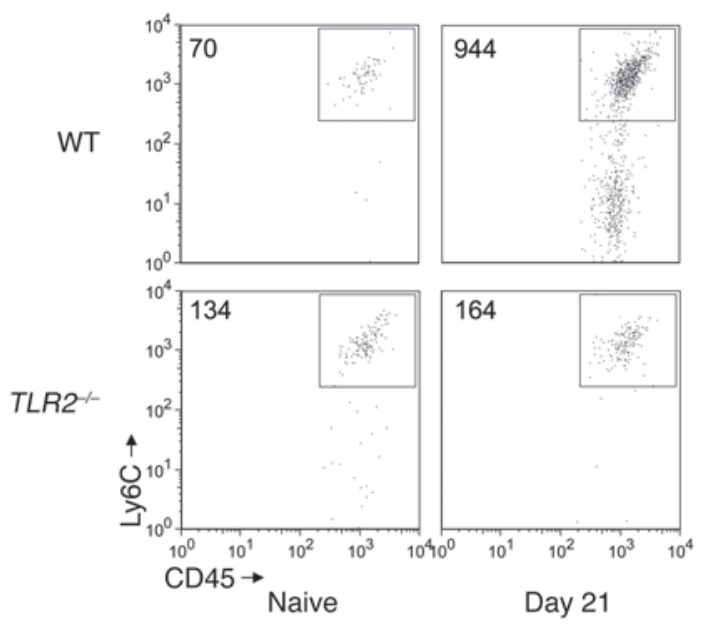

Figure 1

Macrophages are recruited to nasopharynx in association with clearance of pneumococcal isolate P1121, and responses are attenuated in the absence of TLR2 signaling. Upper respiratory tract lavages were analyzed at the time indicated following i.n. inoculation of C57BL/6 WT mice (filled symbols) and congenic TIr2-/- mice (open symbols) for quantitative culture to determine the time course of P1121 colonization (A). Cells in cytospin preparations of colonized mice were used to determine the time course of (B) neutrophil and (C) mononuclear cell recruitment. Animals at day 0 were mock colonized. $n=5$ to 20 mice per group per time point. Values represent means \pm SEM. (D) MOMA-2-positive mononuclear cells are recruited to the lumen of the nasopharynx. MOMA-2 mAb staining (red) of mononuclear cells in the cytospin preparations of nasal lavages from mice 7 days after P1121 challenge with or without Nomarski optics. Isotype-matched antibody was used as a negative control (Neg.). Nuclei were stained with DAPI (blue). Lower right panel shows a mononuclear cell (arrow) and olfactory epithelium lining the nasal cavity in a tissue section stained with H\&E. Original magnification, $\times 1000$ (upper panels); ×400 (lower left panel); ×200 (lower right panel). (E) Quantification by flow cytometry showing a representative experiment comparing the number of infiltrating macrophages in pooled nasal lavages from 5 WT or TIr2 ${ }^{-1-}$ mice at day 21 of P1121 colonization. Naive mice were mock inoculated with PBS. The numbers in the upper left corners indicate the number of $\mathrm{Ly}_{6 \mathrm{C}}{ }^{+}$and $\mathrm{CD} 45^{+}$-double-positive cells in the sample. ${ }^{* \star} P<0.01 ;{ }^{\star \star *} P<0.001$.

tissue, where adaptive immunity may be initiated (24). However, this early influx of neutrophils does not correlate with the decline in the density of pneumococci during colonization, which requires up to several weeks following primary challenge, suggesting that neutrophils may not be the main effectors of clearance (11).

In this report, we characterize the cellular effectors controlling the clearance of mucosal colonization by an extracellular bacterial pathogen. We demonstrate a TLR2-, IL-17A-, and CD4+ $\mathrm{T}$ celldependent recruitment of monocyte/macrophages (primary and secondary colonization) and neutrophils (secondary colonization) into the lumen of the upper airway. Furthermore, we document the contribution of these cells to the clearance of pneumococci from the mucosal surface.

\section{Results}

Monocyte/macrophages promote clearance of colonization. We investigated the cellular immune responses in murine colonization with strain P1121. This type 23F clinical isolate was previously characterized in experimental human carriage and colonizes the nasopharynx of C57BL/6 mice for a similar duration with a similar 
A

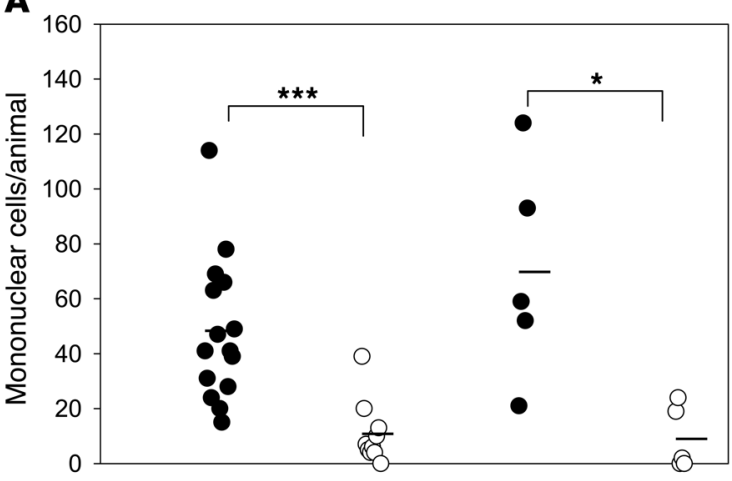

B

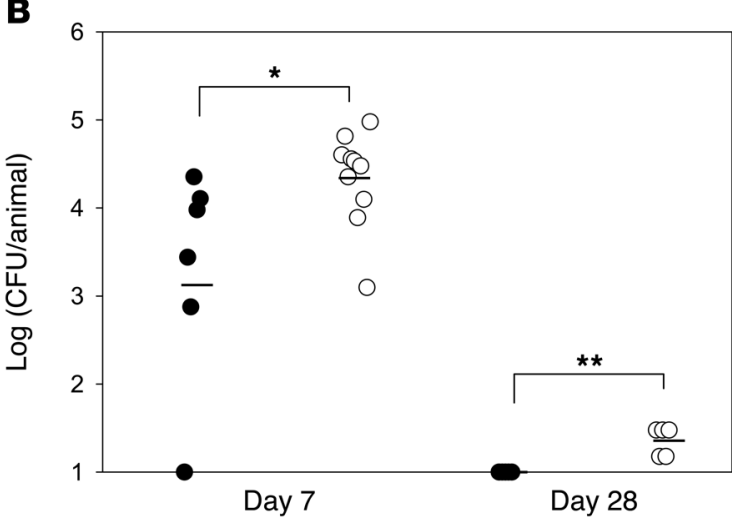

C

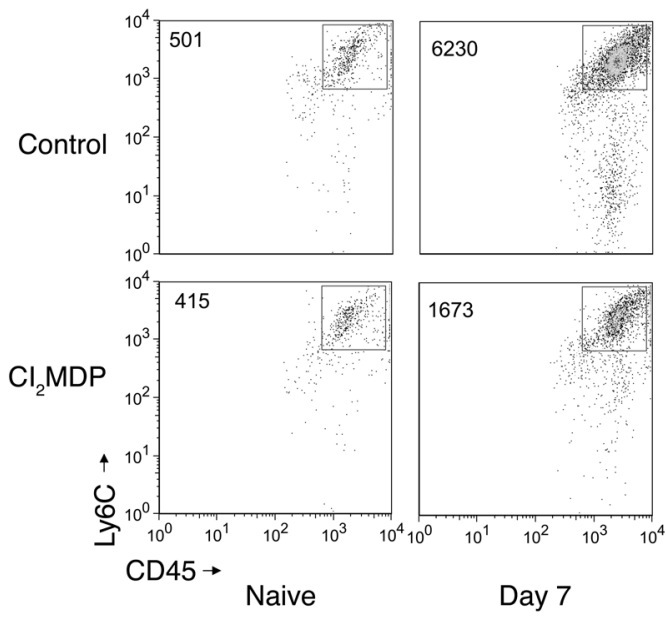

Figure 2

Monocyte/macrophage influx is required for clearance of pneumococcal strain $\mathrm{P} 1121$. Mice were administered liposome- $\mathrm{Cl}_{2} \mathrm{MDP}$ or liposome alone, and the effect of depletion was evaluated at day 7 or 28 after bacterial inoculation as described in Methods. (A) Depletion of mononuclear cells in cytospin preparations as evaluated by differential cell quantification. Closed symbols, liposome; open symbols, liposome-Cl 2 MDP. (B) Effect of monocyte/macrophage depletion on the density of colonization by strain P1121.Values represent individual animals, with the mean shown by a horizontal bar. (C) Quantification of the depletion of monocyte/macrophages at day 7 by flow cytometry. The numbers of CD45+- and Ly6C+-doublepositive events in pooled nasal washes ( $n=5$ per group) at day 7 of P1121 colonization compared with that of naive/PBS mock-colonized control are shown. Mice were administered liposome-Cl 2 MDP (lower panel) or liposome alone as control (upper panel). ${ }^{*} P<0.05 ;{ }^{* \star} P<0.01 ;{ }^{* \star \star} P<0.001$.

immune response $(5,6)$. Upper respiratory tract lavages were used to evaluate the kinetics of colonization by quantitative culture. The cellular inflammatory response to colonization was characterized in lavages by differential cell quantification on cytospin preparations. As previously documented, the density of P1121 decreased gradually over the observation period and was below the limit of detection (10 CFUs/animal) by day 28 after inoculation (Figure $1 \mathrm{~A}$ and data not shown) (11). Numbers of luminal neutrophils were maximal at day 3 after inoculation and thereafter declined to precolonization levels by day 21 after inoculation (Figure 1B). Luminal mononuclear cells, present in precolonized mice in low numbers ( $<10$ cells/animal), reached peak numbers at day 7 after inoculation and remained elevated throughout the remainder of the colonization period (Figure 1C). The mononuclear cells were confirmed to be monocyte/macrophages by staining with monocyte/macrophage marker (MOMA-2) mAbs, which did not bind neutrophils (Figure 1D). Of note, many of the MOMA-2-positive cells had vacuole structures that are typical of activated macrophages (Figure 1D). Recruitment of monocyte/macrophages was confirmed by flow cytometric analysis on nasal lavages pooled from 5 mice at day 7 after inoculation (Figure 1E). The majority of $\mathrm{CD}_{4} 5^{+}$events in nasal lavages stained positively with macrophage marker Ly6C (Figure 1E). Many of the cells also costained with the monocyte marker CD14 (data not shown).
Since the steady decline in the density of colonizing P1121 correlated with the presence of luminal monocyte/macrophages, we addressed whether these cells promote clearance. Liposomes encapsulating clodronate $\left(\mathrm{Cl}_{2} \mathrm{MDP}\right)$ have been used widely to eliminate monocytes and macrophages in the blood, spleen, and liver (24). i.n. administration of $\mathrm{Cl}_{2} \mathrm{MDP}$ liposomes led to a more than $80 \%$ decline in the number of monocyte/macrophages compared with liposome-alone controls as assessed in cytospin preparations at both day 7 and day 28 after inoculation $(P=0.0003$ and 0.01 , respectively; Figure $2 \mathrm{~A})$. There was no significant effect of liposomes with or without $\mathrm{Cl}_{2} \mathrm{MDP}$ on numbers of luminal neutrophils (data not shown). The liposome preparations did not show any significant toxicity to P1121 growth in broth cultures (data not shown). Efficiency of the monocyte/macrophage depletion was also evident by flow cytometric analysis of $\mathrm{CD}_{4} 5^{+}-$and $\mathrm{Ly} 6 \mathrm{C}^{+}$-double-positive events in nasal lavages (Figure 2C). In association with the depletion of monocyte/macrophages, there was diminished clearance of S. pneumoniae at both day 7 and day 28 after inoculation $(P=0.03$ and $P=0.001$, respectively; Figure $2 \mathrm{~B}$ ).

Next, we determined whether there is a physical association between bacteria and these cells. Confocal microscopy following immunostaining for both monocyte/macrophages and strain P1121 on nasal lavage cytospin preparations from day 7 after inoc- 
A
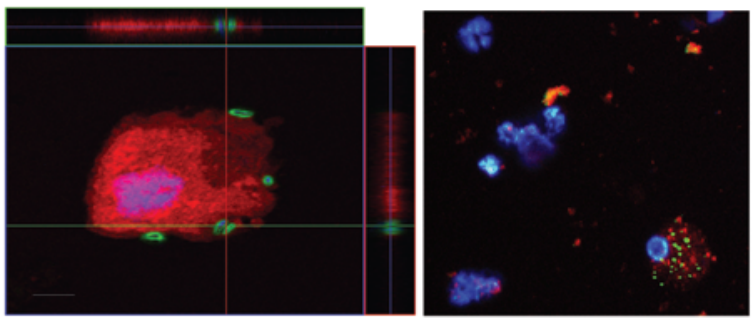

B

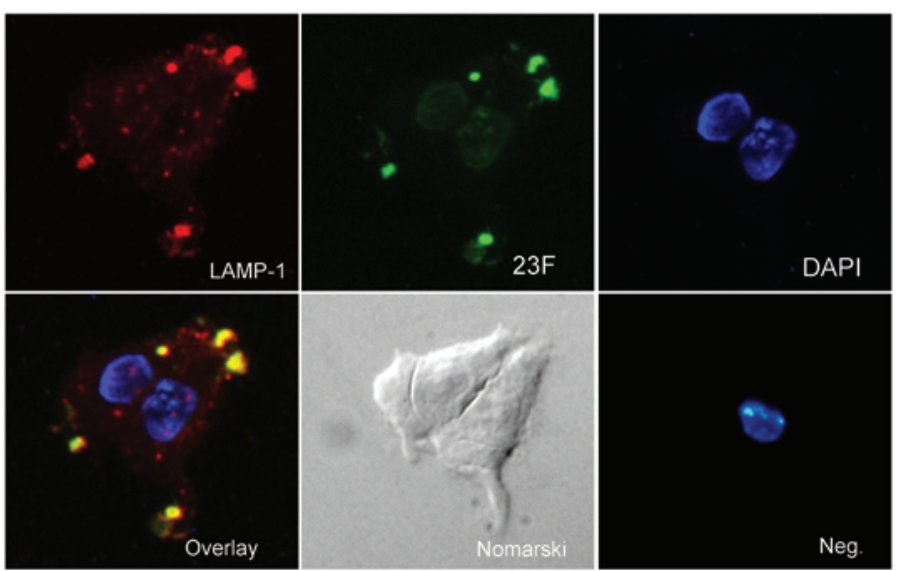

\section{Figure 3}

Macrophages in the lumen of the upper respiratory tract engulf colonizing pneumococci. (A) MOMA-2 mAb staining-positive (red) mononuclear cells associated with pneumococci stained with type $23 \mathrm{~F}$ antiserum (green). Left panel shows a representative z-section confocal image. Cytospin preparations were from mice inoculated with P1121 for 7 days. Scale bar: $5 \mu \mathrm{m}$. Right panel shows representative view of a cytospin preparation from mice inoculated with $\mathrm{P} 1121$ for 3 days. Pneumococci were observed to be associated with monocytes/macrophages but not neutrophils. Original magnification, $\times 200$. (B) P1121 stained with type 23F antiserum (green) colocalized with LAMP-1-positive (red) intracellular lysosomal compartments as shown in the overlay (yellow). Mononuclear cells were identified by DAPI staining of the nucleus (blue). Cytospin preparations were from mice inoculated with P1121 for 7 days. Original magnification, $\times 600$. ulation showed that the pneumococci were commonly engulfed by macrophage-like cells (Figure 3A). No similar association between pneumococci and neutrophils was observed (Figure 3A). In addition, bacteria associated with macrophage-like cells costained with the phagolysosome marker lysosome-associated membrane protein-1 (LAMP-1) (Figure 3B). Together, these findings indicate that bacterial colonization leads to the recruitment of monocyte/macrophages that directly associate with pneumococci and contribute to their clearance following phagocytosis.

Host factors contributing to clearance by monocyte/macrophages during primary infection. The role of TLRs was investigated using $\mathrm{KO}$ mice. As previously reported, $T l r 2^{-/-}$mice were unaffected in early colonization (day 7) but showed delayed clearance at day 21 after inoculation ( $P=0.007$; Figure $1 \mathrm{~A})(18)$. These mice showed a more prolonged influx of neutrophils but no difference in the number of these cells by day 21 after inoculation when defective clearance is observed (Figure 1B). Rather, at this time point and despite an increased number of bacteria, Tlr2 ${ }^{-/}$mice showed impaired recruitment of monocyte/macrophages $(P=0.0004$; Figure $1 \mathrm{C})$. The attenuated recruitment of $\mathrm{CD} 45^{+}-$and $\mathrm{Ly} 6 \mathrm{C}^{+}$-double-positive cells in colonized $\mathrm{Tlr} 2^{-/}$mice was confirmed by flow cytometry on pooled nasal lavages (Figure 1E). In contrast, for TLR4 KO mice (C57BL/10ScNJ), colonization levels of P1121 and monocyte/macrophage recruitment were comparable to those of congenic WT mice (data not shown). These observations suggest that TLR2 but not TLR4 signaling is required for the recruitment of monocyte/ macrophages that mediate clearance.

Likewise, depletion of CD4 ${ }^{+} \mathrm{T}$ cells had no effect on early colonization (day 7; data not shown) but resulted in delayed late clearance at day 21 after inoculation $(P=0.000002$; Figure $4 \mathrm{~A})$. The $\mathrm{CD}^{+} \mathrm{T}$ cell-dependent inhibition of clearance was associated with a decrease in the recruitment of monocyte/macrophages $(P=0.005$; Figure $4 \mathrm{C})$. There was no effect of $\mathrm{CD}^{+} \mathrm{T}$ cell depletion on the density of bacteria or monocyte/macrophage recruitment. Depletion of either $\mathrm{CD}^{+}$or $\mathrm{CD}^{+} \mathrm{T}$ cells showed no effect on neutrophil responses (Figure 4B).

Next, we determined whether the contribution of $\mathrm{CD}^{+} \mathrm{T}$ cells to monocyte/macrophage-mediated clearance required a Th17 response. Systemic depletion of IL-17 during primary colonization using an antibody to murine IL-17A (administered at days 7 and 14 after inoculation) resulted in a loss of bacterial clearance at day 21 after inoculation $\left(P=2 \times 10^{-6} ;\right.$ Figure 4A). Attenuated clearance in anti-IL-17A-treated mice was associated with a complete attenuation of monocyte/macrophage recruitment $(P=0.01$; Figure $4 \mathrm{C})$.

It was concluded that the effects of TLR $2, \mathrm{CD} 4^{+} \mathrm{T}$ cells, and IL-17A on the recruitment of monocyte/macrophages into the airway lumen could account for their previously described role in the clearance of pneumococcal colonization $(11,14,18)$.

Host factors contributing to clearance during secondary infection. Our model of clearance in naive mice predicted that in immune mice, there would be an existing population of pneumococcal-specific IL-17-expressing $\mathrm{CD}^{+} \mathrm{T}$ cells. Cellular responses in primed mice should, in turn, facilitate a more rapid recruitment of phagocytes and clearance. To test this prediction, mice were first challenged i.n. with $10^{7} \mathrm{CFUs}$ of strain P1121, and 6 weeks later, after confirmation of complete nasopharyngeal clearance in pilot experiments, each mouse was given a second i.n. dose of $10^{7}$ CFUs of strain P1121. Analysis of splenocytes from previous colonized mice showed expansion of a population of $\mathrm{CD}^{+} \mathrm{T}$ cells expressing IL-17 in response to pneumococcal stimulation (Figure 5A). This expansion of IL-17-positive cells in splenocytes from previously colonized mice in response to pneumococci was observed in Tlr $2^{+/+}$but not Tlr2 $2^{-/-}$mice (Figure 5, A and B). The expansion of this population in $\mathrm{Tlr} 2^{+/+}$mice correlated with an increase in numbers of lymphocytes in cytospin preparations and $\mathrm{CD}^{+} \mathrm{T}$ cells by flow cytometry in nasal lavages (Figure 5, C and D). 

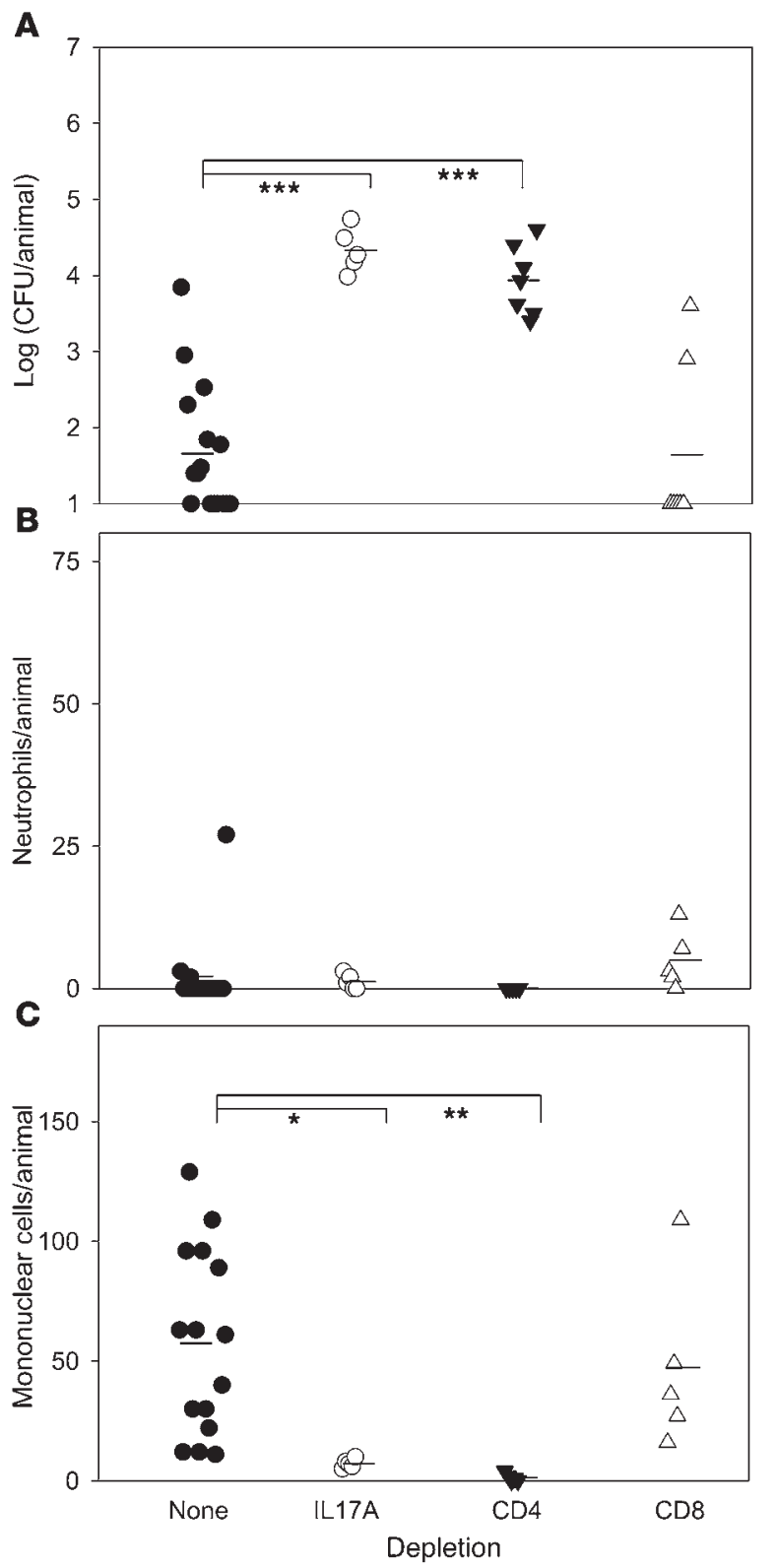

When compared with primary colonization, there was a more rapid clearance of pneumococci during secondary challenge $(P=0.003$ at day 5 after inoculation; Figure 6A). This more rapid clearance was associated with consistently higher numbers of monocyte/macrophages during the observation period, although these differences did not achieve statistical significance until day 5 after inoculation $(P=0.03$; Figure $6 \mathrm{C})$. Associated with the increased recruitment of monocytes/macrophages following secondary challenge, there was an increase in transcription of the CCL2/monocyte chemotactic protein-1 (MCP-1) in the nasal epithelium $(P=0.01$; Figure $6 \mathrm{D})$. Moreover, the increased expression of MCP-1 during secondary challenge was not observed in mice previously depleted of CD $4^{+} \mathrm{T}$ cells or lacking TLR2. Secondary challenge was also associated with an earlier and more robust neutrophil response $(P=0.0006$ at day 1 after inoculation; Figure $6 \mathrm{~B})$. Depletion of $\mathrm{CD}^{+}$but not $\mathrm{CD}^{+} \mathrm{T}$ cells at the time of secondary challenge completely abolished the enhanced early clearance

\section{Figure 4}

Cytokine IL-17A and CD4+ but not $\mathrm{CD}^{+} \mathrm{T}$ cells are required for strain P1121 clearance and monocyte/macrophage recruitment. Mice were administered isotype control antibody (closed circles), IL-17A neutralizing antibody (open circles), 2.43 antibodies to deplete CD8+ $\mathrm{T}$ cells (open triangles), or GK1.5 antibodies to deplete CD4+ T cells (closed triangles) as described in Methods. Nasal lavages were assessed at day 21 after bacterial challenge for (A) density of P1121 colonization, (B) neutrophil recruitment, and (C) monocyte/macrophage recruitment. $n=5-20$ mice per group per time point. Values represent individual animals, with mean shown by a horizontal bar. ${ }^{\star} P<0.05$; ${ }^{* \star} P<0.01 ;{ }^{* \star \star} P<0.001$.

$(P=0.001$; Figure $7 \mathrm{~A})$ as well as the increased monocyte/macrophage $(P=0.001$; Figure $7 \mathrm{C})$ and neutrophil $(P=0.006$; Figure $7 B)$ recruitment associated with reinfection. Similar to depletion of $\mathrm{CD}^{+} \mathrm{T}$ cells, depletion of IL-17A prior to secondary challenge eliminated the increased clearance observed upon reinfection $(P=0.02$; Figure 7A). Depletion of IL-17A, furthermore, blocked recruitment of both neutrophils $(P=0.02$; Figure $7 \mathrm{~B})$ and monocyte/macrophages $(P=0.008$; Figure $7 C)$ into the nasal spaces. Previously, we had reported that the depletion of Ly6G-expressing neutrophil-like cells using the mAb RB6-8C5 has a minimal impact on colonization during primary challenge (24). During secondary challenge, however, treatment with RB6-8C5, which was effective at depleting neutrophils without affecting monocyte/ macrophages, inhibited early clearance $(P=0.03$; Figure $7 \mathrm{~A})$.

Taken together, these data suggest that primary challenge generates $\mathrm{CD}^{+} \mathrm{T}$ cell memory, resulting in enhanced Th17-mediated recruitment of cellular effectors, including both monocyte/macrophages and neutrophils. In contrast with primary colonization, neutrophils recruited in response to secondary challenge contribute to early clearance.

\section{Discussion}

We propose a model for the clearance of $S$. pneumoniae from the mucosal surface of the nasopharynx with many of the features of a delayed-type hypersensitivity response. In particular, our findings demonstrate that bacteria induce $\mathrm{CD} 4^{+} \mathrm{T}$ cell-mediated cellular immunity that is necessary to sustain the local recruitment of nonresident monocyte/macrophages into the upper airway lumen. This infiltration of monocyte/macrophages is prolonged, lasting for several weeks until the organism is no longer detectable, although these cells never appear in large numbers in upper airway lavages. These observations could account for the typical duration and transient nature of episodes of pneumococcal colonization. Several lines of evidence support the conclusion that monocyte/macrophages recruited into the airway lumen act as key effector cells to clear colonizing pneumococci: (a) the time course of recruitment parallels clearance, (b) pharmacologic depletion of these cells impedes clearance, (c) pneumococci are found engulfed by these cells during the time period when the density of colonizing bacteria is declining, and (d) neutralization of each of the host factors needed for monocyte/macrophage recruitment, including TLR2, $\mathrm{CD}^{+} \mathrm{T}$ cells, and IL-17A, results in diminished clearance. Macrophages have been shown to be important in host defense when infection spreads to normally sterile sites, such as the lung, where pneumococci are targeted by alveolar macrophages $(25,26)$. In his classic monograph on pneumococcal pneumonia, Heffron describes "the macrophage reaction" and that "associated with the increasing proportion 
A

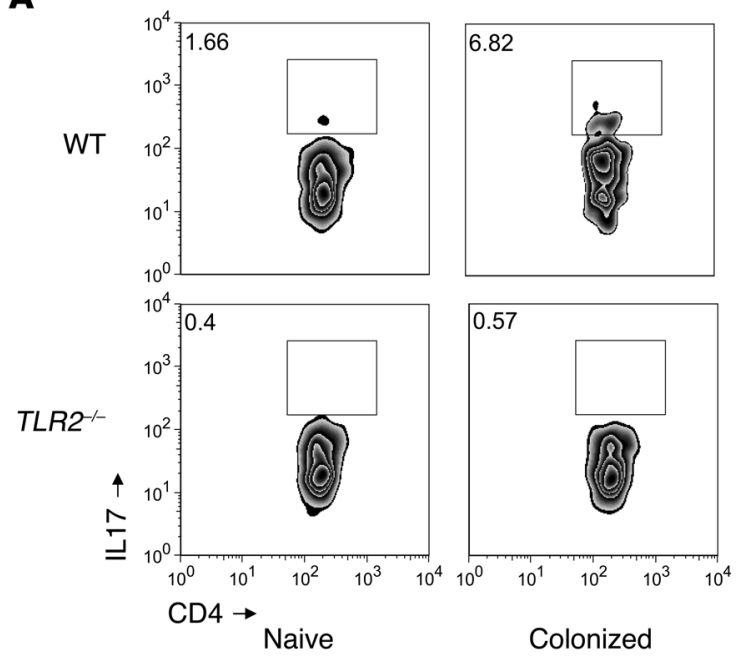

B

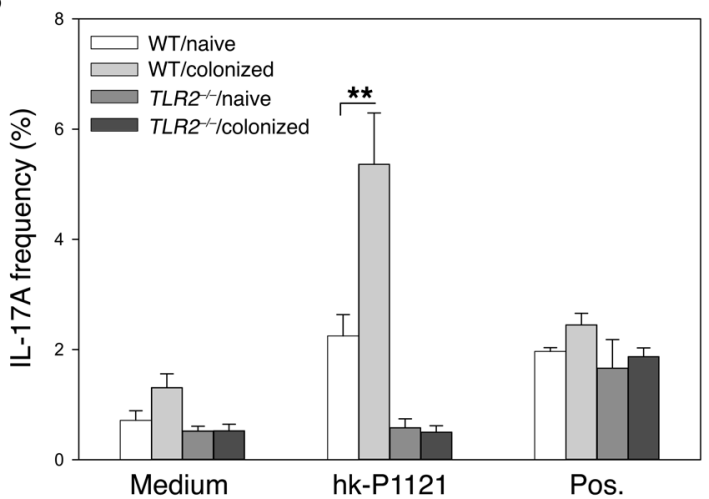

C

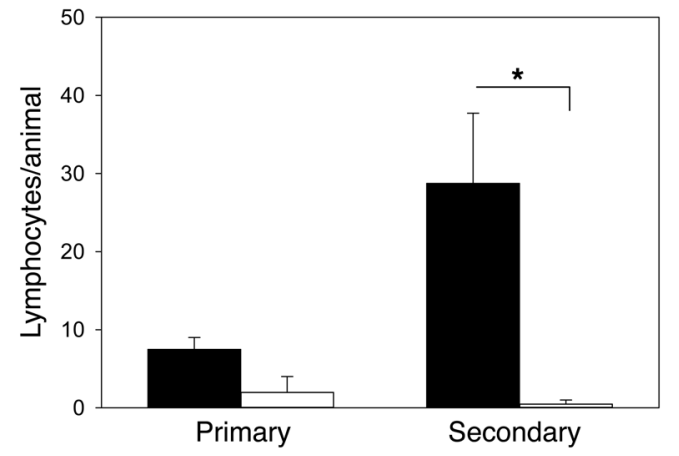

D
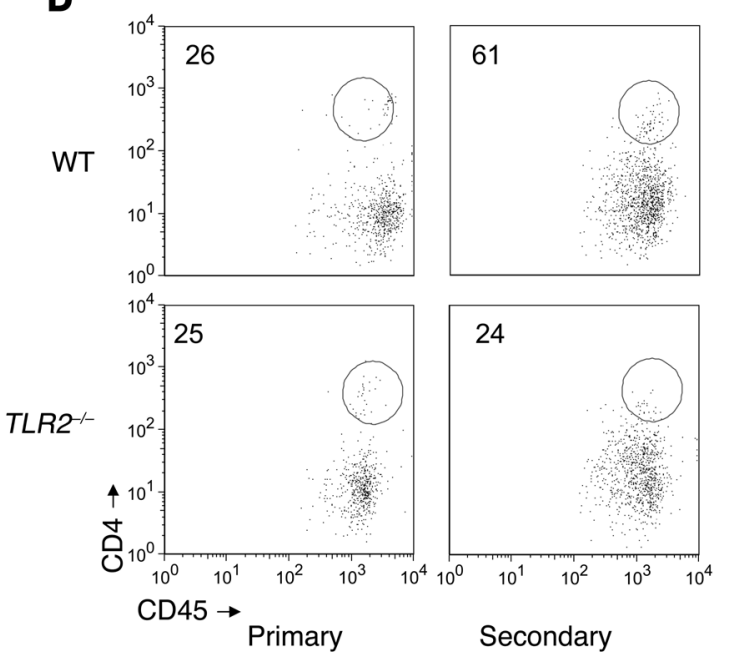

Figure 5

Colonization with strain $\mathrm{P} 1121$ led to mucosal and systemic CD4 ${ }^{+} \mathrm{T}$ cell responses, which were attenuated in the absence of TLR2 signaling. Mice were colonized with strain P1121 (or sham colonized for naive animals) for 6 weeks, and T cell responses to P1121 were analyzed. (A) Systemic Th17 response in P1121-colonized WT but not TIr2--- mice. Splenocytes were stimulated ex vivo with heat-killed P1121 (MOI 50:1), and P1121-specific Th17 response was evaluated by quantification of CD45+- and CD4+-double-positive events through IL-17A intracellular cytokine staining analysis. Representative experiment showing responses in naive and previously colonized WT mice (upper panels) or TIr2 $2^{-/-}$mice (lower panels), with the numbers in the upper left-hand corner indicating the frequencies of IL-17A-producing CD4+ T cells. (B) Combined results of IL-17A intracellular cytokine staining of splenocytes in response to stimulation with heat-killed P1121 (hk-P1121), medium (negative control), and a combination of PMA $(6 \mathrm{nM})$ and ionomycin $(5 \mathrm{nM})$ (positive control [Pos]). (C) Mucosal T cell responses are blunted in T/r2-l- mice. WT (black bars) or TIr2-/- mice (white bars) were challenged with P1121 (primary) or rechallenged with P1121 for 1 day 6 weeks after precolonization (secondary). The number of CD4+ $\mathrm{T}$ cells at the mucosal surface was quantified by differential cell quantification of lymphocytes in cytospin preparations; $n=5$ per group. (D) Representative experiment showing flow cytometric quantification of mucosal CD4+ T cells. Numbers of CD45+- and CD4+-double-positive events in pooled nasal washes are shown in the upper left-hand corners. $n=5$ per group. ${ }^{*} P<0.05 ;{ }^{*} P<0.01$.

of macrophages in the exudates in late resolution there was a concurrent decrease in the number of pneumococci" (27). It has recently been demonstrated that in the course of pneumococcal pneumonia, there is a brisk turnover of resident alveolar macrophages and replacement with newly recruited monocytes $(28,29)$. The present study demonstrates that monocyte/macrophages recruited into the lumen of the upper airway in response to colonization might serve an analogous function in clearing pneumococci in their commensal state.

Several factors were identified as contributing to the mobilization of monocyte/macrophages into the upper airway lumen. There was a requirement for bacteria on the mucosal surface, since numbers of monocyte/macrophages were consistently low in precolonized mice. During the first 3 days of colonization, there is a TLR2- independent influx of monocyte/macrophages and neutrophils. Epithelial surfaces initiate proinflammatory responses to colonizing microbes that result in the elaboration of chemokines and cytokines. For example, 2 epithelial cell-originated antimicrobial peptides, S100A8 and S100A9, have recently been shown to possess chemotactic properties that are required for efficient recruitment of phagocytes, such as macrophages and neutrophils, into the lung in a streptococcal pneumonia mouse model (30). Additional data in this report demonstrate a critical role for TLR2-mediated signaling and $\mathrm{CD} 4^{+} \mathrm{T}$ cells in maintaining monocyte/macrophage recruitment during later stages of colonization. TLR2 signaling may be required for efficient antigen presentation and initiation of an effective $\mathrm{T}$ cell response. This could explain why the effect of TLR2 is observed at day 21 after inoculation but not earlier, as 
A

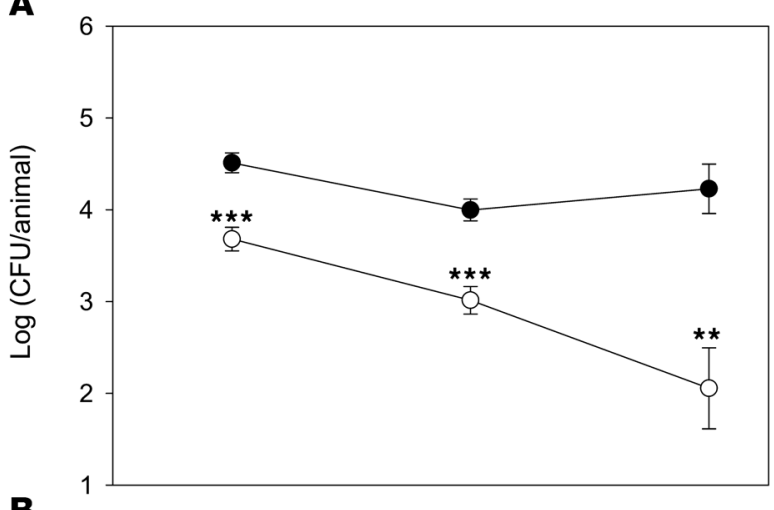

B

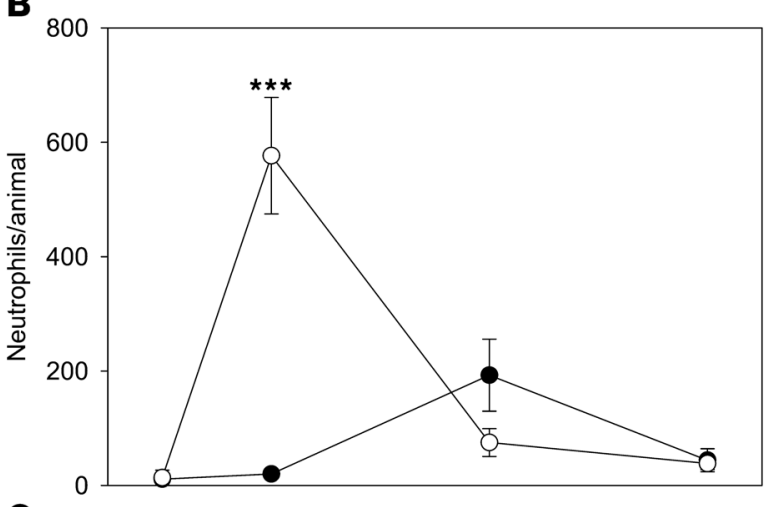

c

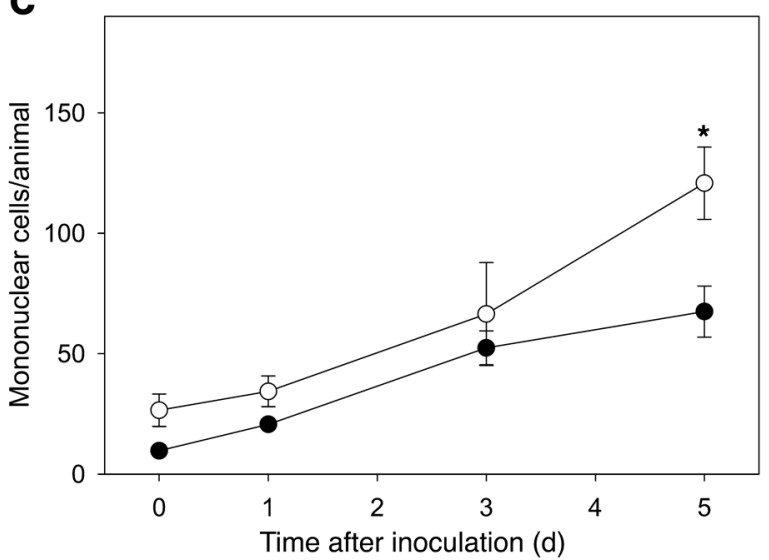

D

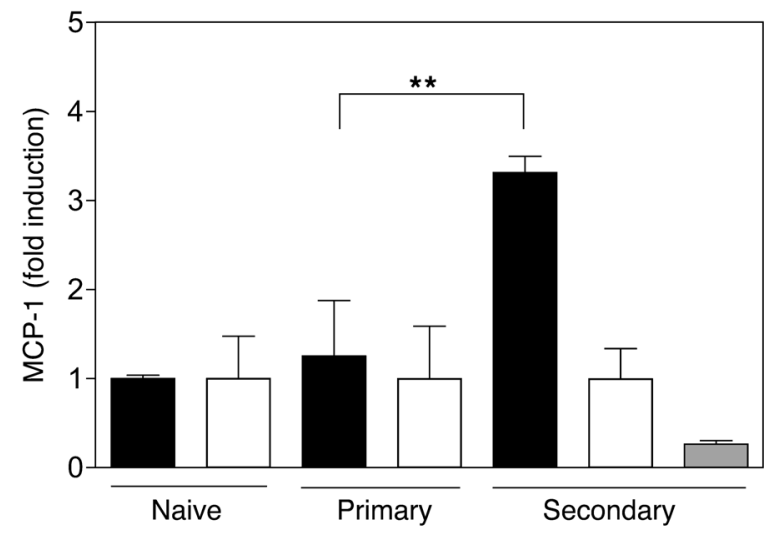

Figure 6

Accelerated clearance in the secondary pneumococcal challenge is associated with enhanced cellular responses. Comparisons of the time course of $(\mathbf{A})$ the density of $\mathrm{P} 1121$ colonization, $(\mathbf{B})$ neutrophil recruitment, and $(\mathbf{C})$ monocyte/macrophage recruitment during primary (closed circles) and secondary (open circles) challenge. $n=5-20$ mice per group per time point. Values represent mean \pm SEM. (D) Quantitative real-time RT-PCR showing increased transcription of chemokine MCP-1 in the colonized epithelium of the nasopharynx. WT (black bars) or Tlr2-/- (white bars) mice were challenged with P1121 (Primary) or rechallenged with P1121 for one day 6 weeks after precolonization (Secondary). WT mice were also treated with GK1.5 antibodies to deplete CD4+ ${ }^{+}$cells (gray bar) prior to rechallenge. $n=4$ mice per group. ${ }^{*} P<0.05,{ }^{* \star} P<0.01 ;{ }^{* *} P<0.001$.

this is prior to the development of adaptive immunity. Helper $\mathrm{T}$ cells transmit signals to monocyte/macrophages to promote killing of intracellular organisms. For typical extracellular pathogens, such as $S$. pneumoniae, the importance and identity of the molecular signals provided by $\mathrm{CD}^{+} \mathrm{T}$ cells to stimulate the recruitment and activity of the monocyte/macrophage effectors have not been established. The predominant IgG isotypes generated against the major surface protein antigen of strain P1121 are IgG2b and IgG3, sub- types typically generated in a Th1-biased immune response (18). We were unable, however, to demonstrate any contribution of the Th1 cytokine IFN- $\gamma$, since mice lacking its receptor show normal clearance of colonization (data not shown). Th17 cells, a subset of $\mathrm{CD}^{+} \mathrm{T}$ cells, are characterized by the ability to generate IL-17A, a cytokine responsible for governing both neutrophil- and macrophage-characterized inflammation, especially in chronic immune disorders or infections of the respiratory tract (31-33). Early pneu- 
A

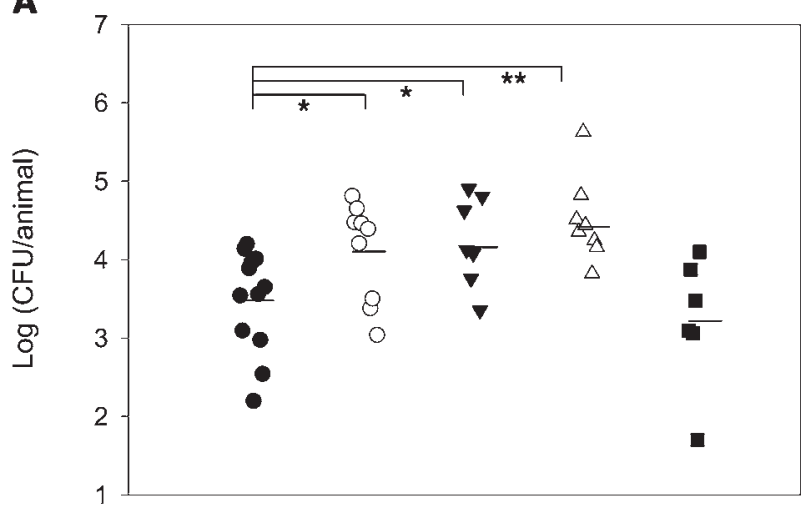

B

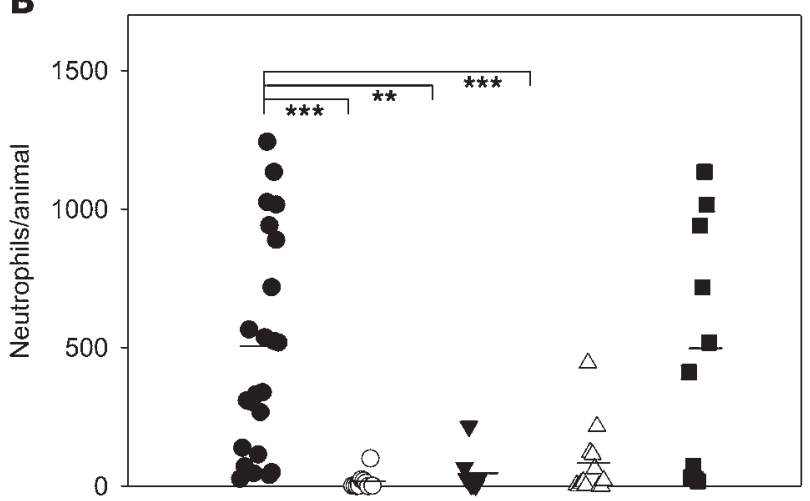

C

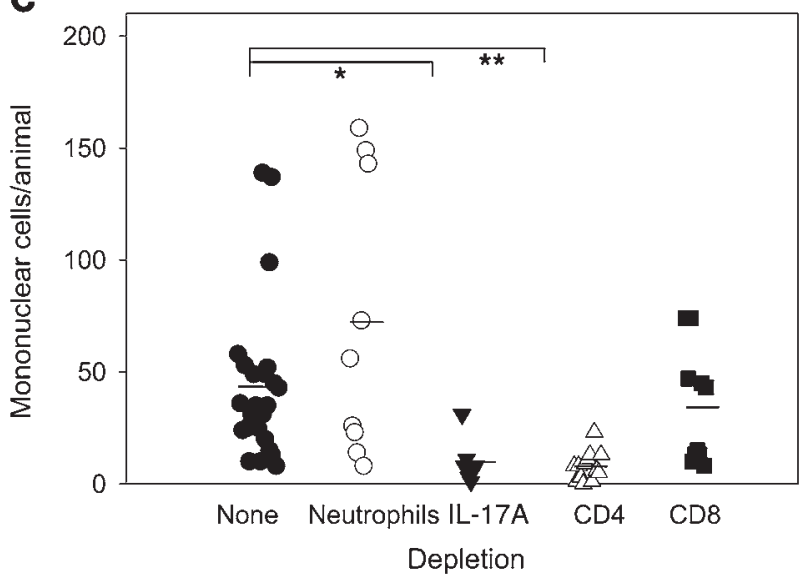

mococcal colonization stimulates transcription of IL- 6 in the nasal epithelium, a response that may contribute to the induction of IL-17-expressing cells (34). It has been suggested that IL-17 is produced systemically while it exerts proinflammatory effects locally through regulation of epithelial cells that are able to express a broad spectrum of chemokines recruiting immune effector cells, including neutrophils and macrophage precursor cells (35-37). In this study, the expression of MCP-1, a chemokine that can recruit monocytes in a Th17-dependent manner, was increased during secondary pneumococcal challenge (31). Endogenous production of IL-17, moreover, has been proposed as a recruitment factor with direct chemotactic effects on blood monocytes (37). Colonization was shown to induce a population of IL-17-expressing $\mathrm{CD}^{+}$ $\mathrm{T}$ cells reactive with pneumococci. Moreover, our study indicates that an IL-17-expressing subpopulation of $\mathrm{CD}^{+} \mathrm{T}$ cells mediates

\section{Figure 7}

Host factors required for accelerated pneumococcal clearance during secondary challenge. Nasal lavages were assessed at 1 day following secondary challenge for (A) density of P1121 colonization, (B) neutrophil recruitment, and (C) monocyte/macrophage recruitment. Prior to rechallenge, mice were treated with RB6-8C5 mAbs to deplete Ly6G-positive neutrophil-like cells, anti-IL-17A to neutralize IL-17A, 2.43 antibodies to deplete CD8 ${ }^{+} \mathrm{T}$ cells, or GK1.5 antibodies to deplete $\mathrm{CD}^{+} \mathrm{T}$ cells and compared with untreated controls. Values represent individual animals, with the mean shown by a horizontal bar. ${ }^{*} P<0.05$; ${ }^{\star *} P<0.01 ;{ }^{* * \star} P<0.001$.

the recruitment of luminal monocyte/macrophages (primary and secondary challenge) and neutrophils (secondary challenge). Our study, therefore, expands on the reports by Malley and coworkers of a Th17 cell response to pneumococcal antigens, to demonstrate that during the natural course of pneumococcal colonization, these cells are critically required for the recruitment of phagocytes that leads to the clearance of colonization in both naive and immune hosts (38). Our findings about pneumococcal colonization, furthermore, are consistent with reports demonstrating that Th17 responses are critical for immunity to extracellular bacterial pathogens during infection (39).

A further question is how monocyte/macrophages recruited into the airway lumen recognize bacterial targets. Previous reports suggest that their function in clearing bacteria from the mucosal surface is not likely to require the presence of specific antibody coating of target organisms during primary colonization $(11,14)$. Complement components could act as opsonins to facilitate phagocytosis (40). It has also been suggested that early clearance from the lung by alveolar macrophages may proceed through a complementindependent mechanism (41). Other molecules found in airway secretions, such as $\mathrm{C}$-reactive protein, are capable of opsonizing pneumococci (42-44). In addition, surface components of monocyte/macrophages, including the C-type lectin SIGNR1, pulmonary surfactant proteins of the collectin family, and the scavenger receptor MARCO, that promote direct recognition and phagocytosis of pneumococci have been described (45-47).

In naive mice, the acquisition of bacteria in the upper airway induces an influx of neutrophils. This acute inflammatory response, however, is insufficient to clear the organism from the mucosal surface (24). A subsequent process that involves $\mathrm{CD} 4^{+} \mathrm{T}$ cell-dependent recruitment of monocyte/macrophages is required to target persisting bacteria following the resolution of the acute inflammatory response during initial colonization. The situation in previously exposed mice, which acquire $\mathrm{CD} 4^{+} \mathrm{T}$ cell memory, appears to be distinct, as there is an earlier IL-17A-dependent influx of professional phagocytes. After secondary challenge, the neutrophil influx, in particular, occurs more quickly and is of a greater magnitude. Importantly, in contrast with the response in naive mice, the neutrophil response during secondary challenge contributes to early bacterial clearance. This finding in secondary challenge might be attributable to opsonizing antibody in immune mice that facilitates phagocytosis when neutrophils are present. In primary challenge, on the other hand, the influx of neutrophils occurs before neutralizing antibody is generated.

In summary, our study provides insight into the events leading to clearance of pneumococcal carriage and offers a new paradigm for understanding how colonizing microbes are targeted by cellular immunity. 


\section{Methods}

Reagents. Anti-mouse macrophage/monocyte mAbs (clone: MOMA-2) were purchased from AbD Serotec. Rabbit serum against pneumococcus group 23 was purchased from Statens Serum Institut. Peridinin chlorophyll protein (PerCP) or allophycocyanin-conjugated (APC-conjugated) anti-mouse CD4 antibody (clone: L3T4 or RM4-5) and FITC-conjugated anti-mouse Ly6C antibody (clone: AL-21) were bought from BD Biosciences - Pharmingen. PE-conjugated anti-mouse CD14 antibody (clone: Sa2-8) and anti-mouse lysosomal marker LAMP-1/CD107a mAb (clone: $1 \mathrm{D} 4 \mathrm{~B})$ were purchased from eBioscience. APC- and PE-conjugated antimouse CD45 antibody (clone: 30-F11), FITC-conjugated anti-mouse IL-17A antibody (clone: TC11-18H10.1), FITC-conjugated isotype control rat IgG1 (clone: RTK2071), and PerCP-conjugated anti-mouse Ly6G antibody (clone: RB6-8C5) were purchased from BioLegend. Cy3-conjugated anti-rat IgG and Cy2-conjugated anti-rabbit IgG secondary antibodies were purchased from Jackson ImmunoResearch Laboratories Inc. Chemicals used to prepare liposomes and liposomes encapsulating clodronate, dichloromethylene diphosphonate $\left(\mathrm{Cl}_{2} \mathrm{MDP}\right.$-liposomes) were all purchased from Sigma-Aldrich.

Mice. C57BL/6 (WT) mice were purchased from The Jackson Laboratory. C57BL/6 Tlr $2 \mathrm{KO}$ mice were created by targeted disruption of the mouse $T l r 2$ gene through replacement of a part of the exon that encodes the transmembrane and the cytoplasmic domain of TLR2 with the neo gene (48). Genetically defined mice were provided by James M. Wilson (University of Pennsylvania). Experiments using animals were approved by the Institutional Animal Care and Use Committee of the University of Pennsylvania. All mice were housed in accordance with IACUC protocols. Water and a standard rodent diet were provided ad libitum. Six- to eight-week-old male and female mice were used for each study.

Pneumococcal strain and colonization. S. pneumoniae strain P1121, isolated from the nasopharynx of a subject enrolled in the human experimental carriage study, is a derivative of P833, the minimally passaged type $23 \mathrm{~F}$ isolate originally obtained from a child with otitis media (6). Unlike its parent P833, which expresses a secreted, truncated form of pneumococcal surface protein A (PspA), P1121 expresses a full-length, surface-attached PspA. P1121 also has a mixed phenotype of opaque and transparent colonies as do most clinical isolates (49). P1121 was grown in $10 \mathrm{ml}$ tryptic soy broth (Difco; $B D)$ until mid-log phase was reached $\left(\mathrm{OD}_{620}=0.5\right)$. After centrifugation, the pellet was resuspended in $1 \mathrm{ml}$ sterile PBS to a density of $10^{9} \mathrm{CFUs} / \mathrm{ml}$.

In the colonization (primary challenge) studies, $10 \mu \mathrm{l}\left(10^{7} \mathrm{CFUs}\right)$ of the pneumococcal suspension was instilled atraumatically into the nares of each mouse. After a predetermined number of days, mice were sacrificed by $\mathrm{CO}_{2}$ asphyxiation. The trachea was exposed and cannulated for instillation of $500 \mu \mathrm{l}$ of sterile PBS. The lavage fluid exiting the nares was collected and P1121 was quantified by plating $10 \mu \mathrm{l}$ serial dilutions of the nasal wash onto tryptic soy agar plates supplemented with catalase (4,741 U/plate) (Worthington Biochemical Corp.) and incubated overnight at $37^{\circ} \mathrm{C}$ in a $5 \% \mathrm{CO}_{2}$ atmosphere. Neomycin $(20 \mu \mathrm{g} / \mathrm{ml})$ was added to plates to inhibit the growth of contaminants.

In the recolonization (secondary challenge) studies, mice were inoculated i.n. with $10^{7} \mathrm{CFUs}$ /animal of P1121 initially. Six weeks later, a time at which nasopharyngeal colonization has been shown to be completely cleared (50), the mice were given a second i.n. dose of $10^{7} \mathrm{CFUs} /$ animal of P1121. Colonization after the second challenge was determined as described above. The limit of detection in colonization studies was $10 \mathrm{CFUs/animal.}$

Differential cell quantification. $500 \mu \mathrm{l}$ of sterile PBS was used for the nasal lavages. All of the lavage fluid exiting the nares $(\sim 400-450 \mu l)$ was used for differential cell quantification and to calculate the total number of cells per animal. Nasal lavage fluid was applied to Colorfrost Plus Microscope
Glass Slides using the Shandon Cytospin 3 cytocentrifuge (Thermo Scientific) at $230 \mathrm{~g}$ for 10 minutes. The cytospin preparations were air dried briefly and subjected to 3-step differential staining using Kwik-Diff Staining Kit (Shandon; Thermo Scientific). Quantification of differential cell types was performed by counting the cells based on standard morphologic criteria at a magnification of $\times 400$. The absolute total number of a given cell type in a cytospin sample was used for data analysis.

Histology and immunocytochemistry. For histology, 7 days after inoculation, mice were sacrificed and decapitated. Heads were first fixed for 48 hours in neutral buffered formalin solution $10 \%$, which contains formaldehyde, $4 \% \mathrm{w} / \mathrm{v}$ (Sigma-Aldrich), and then decalcified for 30 days in $0.12 \mathrm{M} \mathrm{EDTA} \mathrm{(pH} \mathrm{7.0).}$ The heads were frozen in Tissue-Tek OCT Embedding Medium (Electron Microscopy Sciences). Six-micron-thick sections were cut and stained with H\&E. Pictures were captured by a light microscope connected with a high-resolution charge-coupled device CoolSnap digital camera (Roper Scientific).

For immunocytochemistry, cytospin preparations of pooled nasal lavages prepared as described above and dried overnight before fixation were permeabilized with freshly made methanol/acetone $(1: 1$ in volume $)$ at $-20^{\circ} \mathrm{C}$ for 5 minutes. After thorough washing with PBS and treatment with protein blocking reagent (Immunotech; Beckman Coulter) for 10 minutes, the slides were incubated with primary antibody MOMA-2 at a 1:100 dilution in PBT (PBS containing $0.1 \%$ BSA, $0.2 \%$ Triton $\mathrm{X}-100$ ) at $37^{\circ} \mathrm{C}$ for 2 hours. After washing in PBS, the slides were stained with Cy3-conjugated donkey anti-rat IgG secondary antibody at a 1:600 dilution at $37^{\circ} \mathrm{C}$ for 1 hour. Negative staining controls included the omission of the primary antibodies or substitution of the primary antibodies with species-specific and isotypematched IgG. After thorough washing in PBS, slides were mounted with VECTASHIELD Mounting Medium containing DAPI (Vector Laboratories). For coimmunostaining, the above protocol was modified by a replacement of the primary antibody with cocktails of MOMA-2 (1:100) or 2/11 (1:50) mixed with rabbit serum against pneumococcus type $23 \mathrm{~F}$ (1:500) and then a replacement of the secondary antibodies with a mixture of Cy3-conjugated anti-rat IgG (1:600) and Cy2-conjugated anti-rabbit IgG (1:400).

Immunofluorescence and differential interference contrast (DIC, also known as Nomarski) imaging of the samples was processed on a Nikon Eclipse E600 (Nikon Instruments Inc.), which was equipped with a liquid crystal (Micro*Color RGB-MS-C; CRi Inc.) and a charge-coupled device digital camera with Nomarski optics. All image analysis was carried out using iPLab (Scanalytics; BD).

Confocal immunofluorescence imaging of the samples was processed by Zeiss LSM 510 META Confocal System (Carl Zeiss MicroImaging; Zeiss), which included a Zeiss Axiovert $200 \mathrm{M}$ inverted fluorescence microscope operated through the software Zeiss LSM 510 META, version 3.2. The laser sources included coherent chameleon infrared laser with laser lines at $720 \mathrm{nM}$ (blue channel), argon laser with laser lines set at $488 \mathrm{nM}$ (green channel); and $\mathrm{HeNe} 1$ laser with 543-nM laser lines (red channel). The samples were examined and the images were captured through the objective lens $\times 63$ Plan-Apochromat immersed in oil at a total magnitude of $\times 1000$. ImageBrowser 4.0 (Carl Zeiss MicroImaging; Zeiss) was used for viewing and converting Zeiss confocal images. Velocity 4.0 (Improvision; PerkinElmer) was used to refine the images when necessary.

Flow cytometry. Nasal lavages were pooled from at least 5 mice and the cells collected by centrifugation at $1200 \mathrm{~g}$ for 10 minutes at $4^{\circ} \mathrm{C}$. The pellets were washed once using $500 \mu \mathrm{l}$ washing buffer (PBS supplemented with $1 \% \mathrm{BSA})$, collected again by centrifugation, resuspended in $70 \mu \mathrm{l}$ washing buffer, and transferred to a round-bottom 96-well polypropylene plate. A $10 \mu \mathrm{l}$ cocktail of fluorophore-conjugated antibodies recognizing different cell surface proteins was added. Typical final dilutions of the antibodies included 1:400 for APC-CD45 antibody and 1:200 for PerCP-CD4, FITCLy6C, PE-CD14, and APC-Ly6G antibodies. Reactions were carried out by 
incubating the plate on ice in the dark for 45 minutes. $200 \mu$ l of washing buffer was added to terminate the reaction. The pellets were collected and washed again with $200 \mu \mathrm{l}$ washing buffer. All samples were resuspended in the wash buffer and subjected in full volume to flow cytometry analysis on a BD FACSCalibur flow cytometer (BD Biosciences). Buffy coats were obtained from mouse blood as previously described (51). All flow cytometry data were analyzed using FlowJo Mac, version 8.1.1 (Tree Star).

Macrophage depletion. Macrophages were depleted using liposome- $\mathrm{Cl}_{2} \mathrm{MDP}$ as previously described (52). The multilamellar liposomes encapsulating $\mathrm{Cl}_{2} \mathrm{MDP}$ or empty control liposomes were prepared using highly purified chemicals as described in reagents following the protocol described by Nico van Rooijen (52). Depletion was carried out in 2 schemes. For mice analyzed at day 7 after bacterial inoculation, liposome- $\mathrm{Cl}_{2} \mathrm{MDP}(20 \mu \mathrm{l} /$ dose $)$ was given i.n. in 2 doses at days 1 and 4 after P1121 challenge. Alternatively, for mice analyzed at day 28 after bacterial inoculation, liposome- $\mathrm{Cl}_{2} \mathrm{MDP}(20 \mu \mathrm{l} /$ dose $)$ was given in 5 i.n. doses at days 1, 4, 8, 15, and 22 after P1121 challenge. Control mice were given the same doses of liposomes prepared without $\mathrm{Cl}_{2} \mathrm{MDP}$.

$T$ cell depletion. Previously described hybridoma cell lines GK1.5 (antimouse CD4) and 2.43 (anti-mouse CD8) mAbs were purified from cell culture supernatants by affinity chromatography using recombinant protein $\mathrm{G}$ agarose (Life Technologies) (53). Depletion of $\mathrm{CD} 4^{+}$or $\mathrm{CD}^{+}$subsets of $\mathrm{T}$ cells in vivo was achieved by i.p. injection of $\mathrm{mAb}$ GK1.5 or 2.43, respectively, and was carried out in 2 schemes. For time points at day 7 after bacterial inoculation, mice were given a total of $0.6 \mathrm{mg} /$ animal divided in 3 i.p. doses 1 day prior to and 1 and 3 days after i.n. challenge with P1121. For time points at day 21 after bacterial inoculation, mice were given a total of $1.2 \mathrm{mg}$ /animal divided into 6 i.p. doses administered 1 day prior to and $1,3,8,12$, and 18 days after i.n. challenge with P1121. As analyzed by flow cytometry of the splenocytes at the time of sacrifice, all depletion schemes resulted in a depletion of $\mathrm{CD}^{+}$or $\mathrm{CD} 8^{+} \mathrm{T}$ cells of over $99.5 \%$.

Neutrophil depletion. Affinity-purified anti-mouse Ly6G mAb RB6-8C5 (Rockland Immunochemicals) was prepared from ascites of nude mice given the RB6-8C5 rat hybridoma as previously described (54). To deplete neutrophil-like cells, $150 \mu \mathrm{g}$ of mAbs per mouse was administered i.p. 24 hours prior to bacterial challenge. This dose was previously shown to result in peripheral blood neutropenia ( $<50$ granulocytes/ $\mu$ l) for a period of at least 96 hours (54). Controls were given the equivalent i.p. dose of total rat IgG (Sigma-Aldrich).

Neutralization of IL-17A. For experiments carried out during primary pneumococcal colonization, mice were given 2 i.p. injections ( $100 \mu \mathrm{g} / \mathrm{dose})$ of a rat $\mathrm{mAb}$ to murine IL-17A at days 7 and 14 after inoculation with P1121 and were sacrificed at day 21 to obtain nasal lavages (15). For experiments carried out during secondary pneumococcal colonization, 6 weeks following initial colonization, mice received anti-mouse IL-17A in 2 doses $(100 \mu \mathrm{g} /$ dose $) 1$ day before and at the same time as rechallenge with pneumococci. These mice were sacrificed on day 1 after secondary challenge for analysis of nasal lavages. Control mice received the same dose of rat IgG on the same schedule.

IL-17A intracellular cytokine staining. Single-cell suspensions were prepared from spleens harvested from mice previously colonized (or sham colonized) with strain P1121 by mincing through steel meshes in RPMI 1640 with GlutaMAX (GIBCO; Invitrogen). Red blood cells were lysed with ACK lysing buffer (Cambrex). The splenocytes were washed and resuspended at a concentration of $10^{6}$ cells $/ \mathrm{ml}$ using T cell medium: DMEM with GlutaMAX (GIBCO; Invitrogen) supplemented with 10\% FBS (HyClone; Thermo
Scientific), $10 \mathrm{mM}$ HEPES, $2 \mathrm{mM}$ L-glutamine, $1 \mathrm{mM}$ sodium pyruvate, $0.1 \mathrm{mM}$ MEM nonessential amino acids (GIBCO; Invitrogen), $5 \mu \mathrm{M} 2$-mercaptoethanol, and penicillin-streptomycin (Mediatech Inc.). $100 \mu \mathrm{l}$ of the cells were seeded in round-bottom 96-well plates and stimulated with or without heat-killed P1121 (at a concentration equivalent to MOI 50:1) in the presence of $1 \mu \mathrm{l} / \mathrm{ml}$ GolgiPlug (BD Biosciences - Pharmingen). After an incubation of 6.5 hours at $37^{\circ} \mathrm{C}$ and $10 \% \mathrm{CO}_{2}$, the cells were collected, washed with washing buffer, and subjected to intracellular staining for flow cytometry analysis as described above. In brief, the cells were first stained with a mixture of PE-conjugated anti-mouse CD45 (1:200) and APC-conjugated CD4 (1:400) antibodies in $50 \mu \mathrm{l}$ washing buffer for 45 minutes on ice. Then the cells were permeabilized and stained with FITC-conjugated IL-17A (1:200) or isotype control antibody using BD Cytofix/Cytoperm fixation/permeabilization solution kit (BD Biosciences - Pharmingen) according to the manufacturer's instructions.

Quantitative real-time RT-PCR. Epithelium lining the upper respiratory tract was harvested, and quantitative real-time RT-PCR was performed as previously described (34). In brief, the epithelium was lysed and collected, and RNA isolated using an RNeasy Mini Kit (QIAGEN). 1 to $1.5 \mu \mathrm{g}$ RNA was used for reverse transcription in a $20 \mu \mathrm{l}$ reaction using high-capacity cDNA reverse transcription kit (Applied Biosystems) with random primers and an addition of $20 \mathrm{U}$ RNase inhibitor (Promega). cDNA was diluted at $1: 5$, and $2.5-5 \mu \mathrm{l}$ was used as template with $0.5 \mu \mathrm{M}$ primers and SYBR Green PCR Master Mix in a 20- $\mu$ l reaction (Applied Biosystems). Standard runs of the reactions on fast optical 96-well reaction plates (Applied Biosystems) were carried out using StepOnePlus Real-Time PCR system (Applied Biosystems). Quantitative comparison was obtained through the $\Delta \Delta C_{\mathrm{T}}$ method (55). Primers used were as follows: mGAPDH-F: 5'-TGTGTCCGTCGTGGATCTGA-3'; mGAPDH-R: 5'-CCTGCTTCACCACCTTCTTGAT-3'; mMCP1-F: 5'-AGCTCTCTCTTCCTCCACCAC-3'; and mMCP1-R: 5'-CGTTAACTGCATCTGGCTGA-3'.

Statistics. The data were analyzed using parametric statistical analysis 1-way ANOVA using MicroCal Origin PC software, version 6.0 (MicroCal; GE Healthcare). Results are expressed as means \pm SEM. $P<0.05$ was considered significant.

\section{Acknowledgments}

We thank the Cell Morphology Core of the Gene Therapy Program, the Morphology Core of the Center for the Molecular Studies of Liver and Digestive Diseases (P30 DK50306), and the Biomedical Imaging Facility at the University of Pennsylvania for technical support. We thank Elena Lysenko and Xiaobo Wang for technical assistance. This work was funded by grants from the US Public Health Service (AI44231 and AI38446 to J.N. Weiser).

Received for publication July 9, 2008, and accepted in revised form April 10, 2009.

Address correspondence to: Jeffrey N. Weiser, University of Pennsylvania School of Medicine, 402A Johnson Pavilion, 3610 Hamilton Walk, Philadelphia, Pennsylvania 19104-6076, USA. Phone: (215) 573-3511; Fax: (215) 573-4856; E-mail: weiser@ mail.med.upenn.edu.
1. Cutts, F.T., et al. 2005. Efficacy of nine-valent pneumococcal conjugate vaccine against pneumonia and invasive pneumococcal disease in The Gambia: randomised, double-blind, placebo-controlled trial. Lancet. 365:1139-1146.

2. Kadioglu, A., Weiser, J.N., Paton, J.C., and Andrew, P.W. 2008. The role of Streptococcus pneumoniae virulence factors in host respiratory colonization and disease. Nat. Rev. Microbiol. 6:288-301.

3. Austrian, R. 1986. Some aspects of the pneumococcal carrier state. J. Antimicrob. Chemother. 18:35-45.

4. Bogaert, D., De Groot, R., and Hermans, P.W. 2004. Streptococcus pneumoniae colonisation: the key to pneumococcal disease. Lancet. Infect. Dis. 4:144-154.

5. Syrjanen, R.K., Kilpi, T.M., Kaijalainen, T.H., Herva, E.E., and Takala, A.K. 2001. Nasopharyngeal car- riage of Streptococcus pneumoniae in Finnish children younger than 2 years old. J. Infect. Dis. 184:451-459. 6. McCool, T.L., Cate, T.R., Moy, G., and Weiser, J.N. 2002. The immune response to pneumococcal proteins during experimental human carriage. J. Exp. Med. 195:359-365.

7. Goldblatt, D., et al. 2005. Antibody responses to nasopharyngeal carriage of Streptococcus pneumoniae 
in adults: a longitudinal household study. J. Infect. Dis. 192:387-393

8. MacLeod, C.M., Hodges, R.M., Heidelberger, M., and Bernhard, W.G. 1945. Prevention of pneumococcal infection by immunization with capsular polysaccharides of Streptococcus pneumoniae. J. Exp. Med. 82:445-465.

9. Dagan, R., et al. 2005. Serum serotype-specific pneumococcal anticapsular immunoglobulin $g$ concentrations after immunization with a 9-valent conjugate pneumococcal vaccine correlate with nasopharyngeal acquisition of pneumococcus. J. Infect. Dis. 192:367-376.

10. Mbelle, N., et al. 1999. Immunogenicity and impact on nasopharyngeal carriage of a nonavalent pneumococcal conjugate vaccine. J. Infect. Dis. 180:1171-1176.

11. McCool, T.L., and Weiser, J.N. 2004. Limited role of antibody in clearance of Streptococcus pneumoniae in a murine model of colonization. Infect. Immun. 72:5807-5813.

12. Lipsitch, M., et al. 2005. Are anticapsular antibodies the primary mechanism of protection against invasive pneumococcal disease? PLoS Med. 2:e15.

13. Malley, R., et al. 2004. Multiserotype protection of mice against pneumococcal colonization of the nasopharynx and middle ear by killed nonencapsulated cells given intranasally with a nontoxic adjuvant. Infect. Immun. 72:4290-4292.

14. Malley, R., et al. 2005. CD4+ T cells mediate antibody-independent acquired immunity to pneumococcal colonization. Proc. Natl. Acad. Sci. U. S. A. 102:4848-4853.

15. Malley, R., et al. 2006. Antibody-independent, interleukin-17A-mediated, cross-serotype immunity to pneumococci in mice immunized intranasally with the cell wall polysaccharide. Infect. Immun. 74:2187-2195

16. Trzcinski, K., et al. 2008. Protection against nasopharyngeal colonization by Streptococcus pneumoniae is mediated by antigen-specific CD4+ T cells. Infect. Immun. 76:2678-2684.

17. Madhi, S.A., et al. 2007. Long-term effect of pneumococcal conjugate vaccine on nasopharyngeal colonization by Streptococcus pneumoniae - and associated interactions with Staphylococcus aureus and Haemophilus influenzae colonization--in HIVInfected and HIV-uninfected children. J. Infect. Dis. 196:1662-1666.

18. van Rossum, A.M., Lysenko, E.S., and Weiser, J.N. 2005. Host and bacterial factors contributing to the clearance of colonization by Streptococcus pneumoniae in a murine model. Infect. Immun. 73:7718-7726.

19. Akira, S. 2006. TLR signaling. Curr. Top. Microbiol. Immunol. 311:1-16.

20. Kabelitz, D. 2007. Expression and function of Tolllike receptors in Tlymphocytes. Curr. Opin. Immunol. 19:39-45.

21. Malley, R., et al. 2003. Recognition of pneumolysin by Toll-like receptor 4 confers resistance to pneumococcal infection. Proc. Natl. Acad. Sci. U. S. A. 100:1966-1971.

22. Kadioglu, A., Coward, W., Colston, M.J., Hewitt, C.R., and Andrew, P.W. 2004. CD4-T-lymphocyte interactions with pneumolysin and pneumococci suggest a crucial protective role in the host response to pneumococcal infection. Infect. Immun. 72:2689-2697.
23. Lu, Y.J., et al. 2008. Interleukin-17A mediates acquired immunity to pneumococcal colonization. PLoS Pathog. 4:e1000159.

24. Matthias, K.A., Roche, A.M., Standish, A.J., Shchepetov, M., and Weiser, J.N. 2008. Neutrophiltoxin interactions promote antigen delivery and mucosal clearance of Streptococcus pneumoniae. J. Immunol. 180:6246-6254.

25. Bergeron, Y., et al. 1998. Cytokine kinetics and other host factors in response to pneumococcal pulmonary infection in mice. Infect. Immun. 66:912-922.

26. Sun, K., and Metzger, D.W. 2008. Inhibition of pulmonary antibacterial defense by interferon-gamma during recovery from influenza infection. Nat. Med. 14:558-564.

27. Heffron, R. 1979. Pneumonia, with special reference to pneumococcus lobar pneumonia. Harvard University Press. Cambridge, Massachusetts, USA. 1086 pp.

28. Taut, K., et al. 2008. Macrophage turnover kinetics in the lungs of mice infected with Streptococcus pneumoniae. Am. J. Respir. Cell Mol. Biol. 38:105-113.

29. Maus, U., et al. 2001. Monocytes recruited into the alveolar air space of mice show a monocytic phenotype but upregulate CD14. Am. J. Physiol. Lung Cell Mol. Physiol. 280:L58-L68.

30. Raquil, M.A., Anceriz, N., Rouleau, P., and Tessier, P.A. 2008. Blockade of antimicrobial proteins S100A8 and S100A9 inhibits phagocyte migration to the alveoli in streptococcal pneumonia. J. Immunol. 180:3366-3374.

31. Park, H., et al. 2005. A distinct lineage of CD4 T cells regulates tissue inflammation by producing interleukin 17. Nat. Immunol. 6:1133-1141.

32. Harrington, L.E., et al. 2005. Interleukin 17-producing CD4+ effector $\mathrm{T}$ cells develop via a lineage distinct from the $\mathrm{T}$ helper type 1 and 2 lineages. Nat. Immunol. 6:1123-1132.

33. Bettelli, E., et al. 2006. Reciprocal developmental pathways for the generation of pathogenic effector TH17 and regulatory T cells. Nature. 441:235-238.

34. Beisswenger, C., Lysenko, E.S., and Weiser, J.N. 2009. Early bacterial colonization induces toll-like receptor-dependent transforming growth factor beta signaling in the epithelium. Infect. Immun. 77:2212-2220

35. Miyamoto, M., et al. 2003. Endogenous IL-17 as a mediator of neutrophil recruitment caused by endotoxin exposure in mouse airways. J. Immunol. 170:4665-4672.

36. Kolls, J.K., and Linden, A. 2004. Interleukin-17 family members and inflammation. Immunity. 21:467-476

37. Sergejeva, S., Ivanov, S., Lotvall, J., and Linden, A. 2005. Interleukin-17 as a recruitment and survival factor for airway macrophages in allergic airway inflammation. Am. J. Respir. Cell Mol. Biol. 33:248-253.

38. Basset, A., et al. 2007. Antibody-independent, CD4+ T-cell-dependent protection against pneumococcal colonization elicited by intranasal immunization with purified pneumococcal proteins. Infect. Immun. 75:5460-5464.

39. Aujla, S.J., Dubin, P.J., and Kolls, J.K. 2007. Th17 cells and mucosal host defense. Semin. Immunol. 19:377-382.

40. van Lookeren Campagne, M., Wiesmann, C., and Brown, E.J. 2007. Macrophage complement receptors and pathogen clearance. Cell. Microbiol.
9:2095-2102

41. Rehm, S.R., and Coonrod, J.D. 1982. Early clearance of pneumococci from the lungs of decomplemented rats. Infect. Immun. 36:24-29.

42. Gould, J.M., and Weiser, J.N. 2001. Expression of C-reactive protein in the human respiratory tract. Infect. Immun. 69:1747-1754.

43. Szalai, A.J., Briles, D.E., and Volanakis, J.E. 1995. Human C-reactive protein is protective against fatal Streptococcus pneumoniae infection in transgenic mice. J. Immunol. 155:2557-2563.

44. Gould, J.M., and Weiser, J.N. 2002. The inhibitory effect of C-reactive protein on bacterial phosphorylcholine platelet-activating factor receptor-mediated adherence is blocked by surfactant. J. Infect. Dis. 186:361-371.

45. Kuronuma, K., et al. 2004. Pulmonary surfactant protein A augments the phagocytosis of Streptococcus pneumoniae by alveolar macrophages through a casein kinase 2-dependent increase of cell surface localization of scavenger receptor A. J. Biol. Chem. 279:21421-21430.

46. Koppel, E.A., Litjens, M., van den Berg, V.C., van Kooyk, Y., and Geijtenbeek, T.B. 2008. Interaction of SIGNR1 expressed by marginal zone macrophages with marginal zone B cells is essential to early IgM responses against Streptococcus pneumoniae. Mol. Immunol. 45:2881-2887.

47. Arredouani, M., et al. 2004. The scavenger receptor MARCO is required for lung defense against pneumococcal pneumonia and inhaled particles. J. Exp. Med. 200:267-272.

48. Takeuchi, O., et al. 1999. Differential roles of TLR2 and TLR4 in recognition of gram-negative and gram-positive bacterial cell wall components. Immunity. 11:443-451.

49. Weiser, J.N., Austrian, R., Sreenivasan, P.K., and Masure, H.R. 1994. Phase variation in pneumococcal opacity: relationship between colonial morphology and nasopharyngeal colonization. Infect. Immun. 62:2582-2589.

50. Roche, A.M., King, S.J., and Weiser, J.N. 2007. Live attenuated Streptococcus pneumoniae strains induce serotype-independent mucosal and systemic protection in mice. Infect. Immun. 75:2469-2475.

51. Cotter, M.J., Norman, K.E., Hellewell, P.G., and Ridger, V.C. 2001. A novel method for isolation of neutrophils from murine blood using negative immunomagnetic separation. Am. J. Pathol. 159:473-481.

52. Van Rooijen, N. 1989. The liposome-mediated macrophage 'suicide' technique. J. Immunol. Methods. 124:1-6.

53. Pan, Z.K., Ikonomidis, G., Lazenby, A., Pardoll, D., and Paterson, Y. 1995. A recombinant Listeria monocytogenes vaccine expressing a model tumour antigen protects mice against lethal tumour cell challenge and causes regression of established tumours. Nat. Med. 1:471-477.

54. Lysenko, E.S., Ratner, A.J., Nelson, A.L., and Weiser, J.N. 2005. The role of innate immune responses in the outcome of interspecies competition for colonization of mucosal surfaces. PLoS Pathog. 1:e1.

55. [No authors listed]. 2008. Guide to performing relative quantitation of gene expression using realtime quantitative PCR. Applied Biosystems Inc. Foster City, California, USA. http://www3.appliedbiosystems.com/cms/groups/mcb_support/documents/generaldocuments/cms_042380.pdf. 